\title{
Proteomic insights into the molecular response of Sargassum vulgare to acidification at volcanic CO2 vents
}

\author{
Amit Kumar ${ }^{1}$, Simona Nonnis ${ }^{2}$, Immacolata Castellano ${ }^{1}$, Hamada AbdElgawad ${ }^{3}$, Gerrit \\ Beemster $^{3}$, Maria Cristina Buia ${ }^{1}$, Gabriella Tedeschi², and Anna Palumbo ${ }^{1}$ \\ ${ }^{1}$ Stazione Zoologica Anton Dohrn \\ ${ }^{2}$ University of Milan \\ ${ }^{3}$ Universiteit Antwerpen Departement Biologie
}

July 6, 2020

\begin{abstract}
Ocean acidification is impacting marine life all over the world. Understanding how species are able to cope with the changes of seawater carbonate chemistry represents a challenging issue. We addressed this topic using underwater $\mathrm{CO} 2$ vents that naturally acidify some marine areas occurring off the island of Ischia. There, the brown alga Sargassum vulgare dominates the most acidified area, showing a $\mathrm{pH}$ value of 6.7 , comparable to future, i.e. 2300 , acidification scenarios. The novelty of the present study is the characterization of the S. vulgare proteome as response to ocean acidification. A total of 584 and 535 proteins were characterized in populations grown on current $\mathrm{pH}$ and acidified sites, respectively. 507 Proteins were significantly expressed in samples from both sites: 41 proteins were either up-regulated or exclusively present under acidified conditions, whereas 108 proteins were either down-regulated in the acidified site or present only under control conditions. Functionally, a decrease in proteins related to transcription and translation, and ER/Golgi trafficking and vesicular transport was observed under acidification. The up-regulated proteins are involved in the photosynthetic process and stress response. In addition, aminoacids metabolism was affected, which was reflected in their levels. Analyses of other metabolites revealed variations in the levels of some fatty acids and phenols. Overall, the results obtained by proteomics and metabolites analysis, integrated with previous transcriptomic, physiological and biochemical studies, have allowed to delineate the molecular strategies adopted by S. vulgare to grow in future acidified environments.
\end{abstract}

\section{Hosted file}

Kumar_manuscript.docx available at https://authorea.com/users/337763/articles/467398proteomic-insights-into-the-molecular-response-of-sargassum-vulgare-to-acidi $\% E F \% A C \%$ 81cation-at-volcanic-co2-vents 


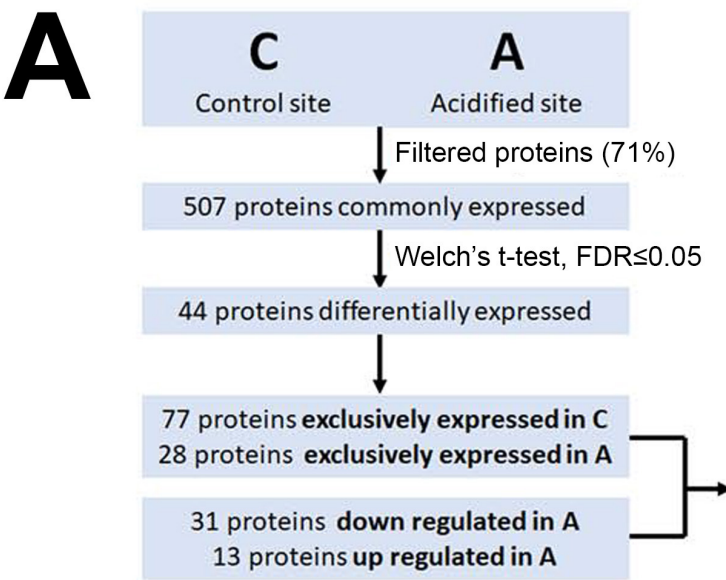

13 proteins up regulated in $A$

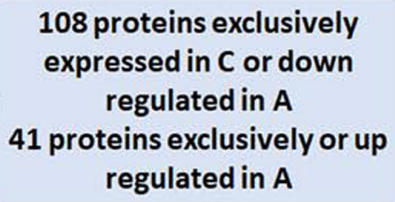

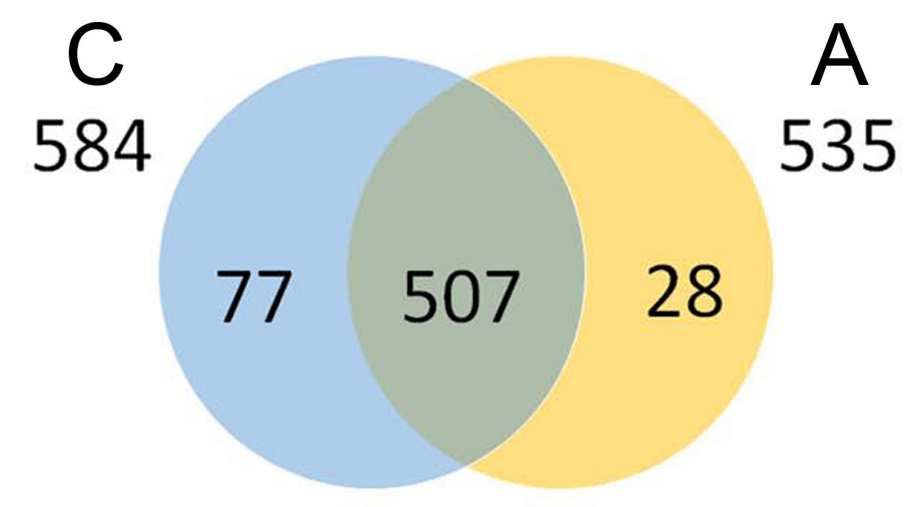

C

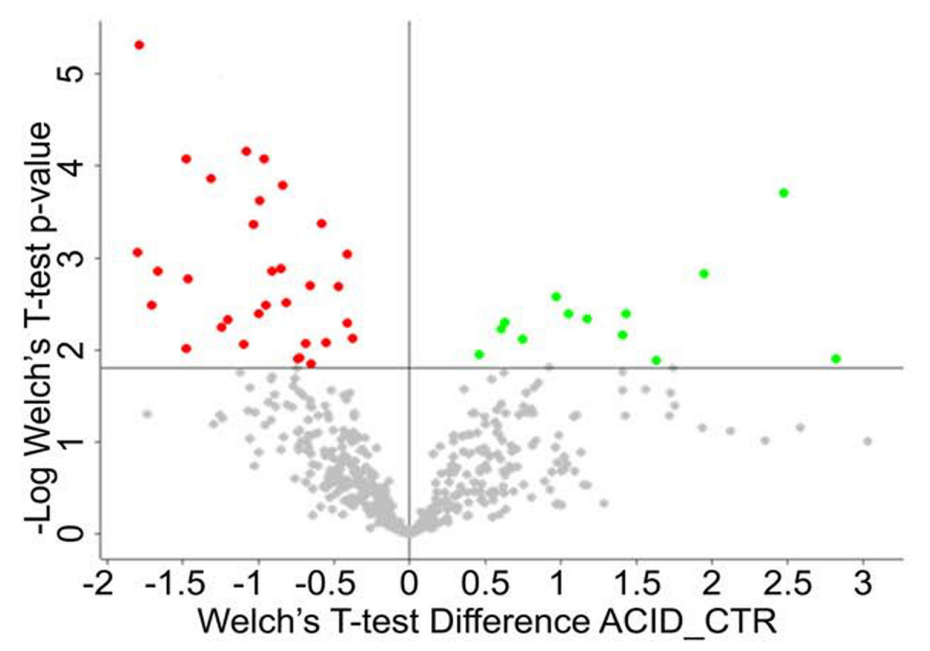



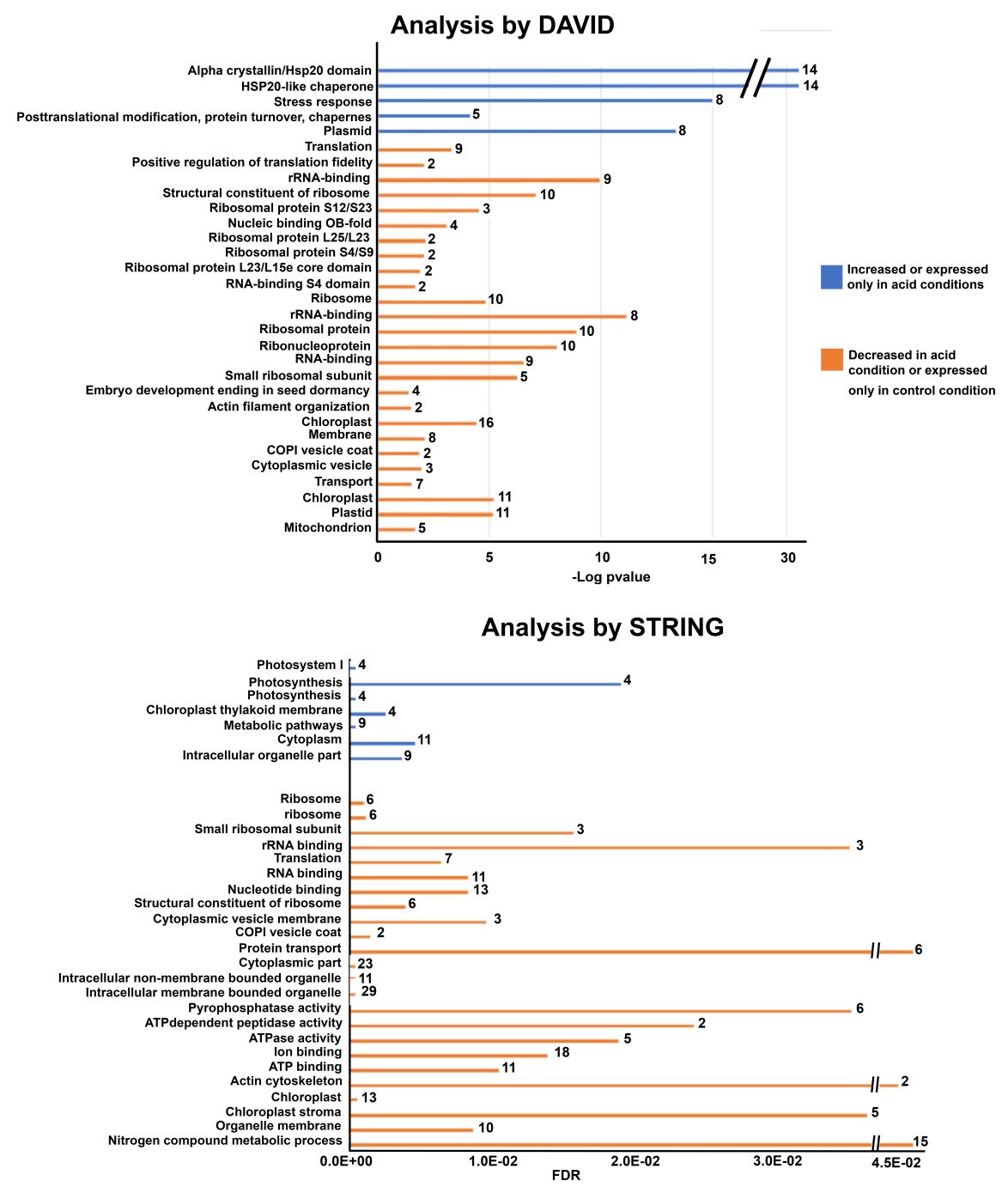
Analysis by PANTHER (Classification)

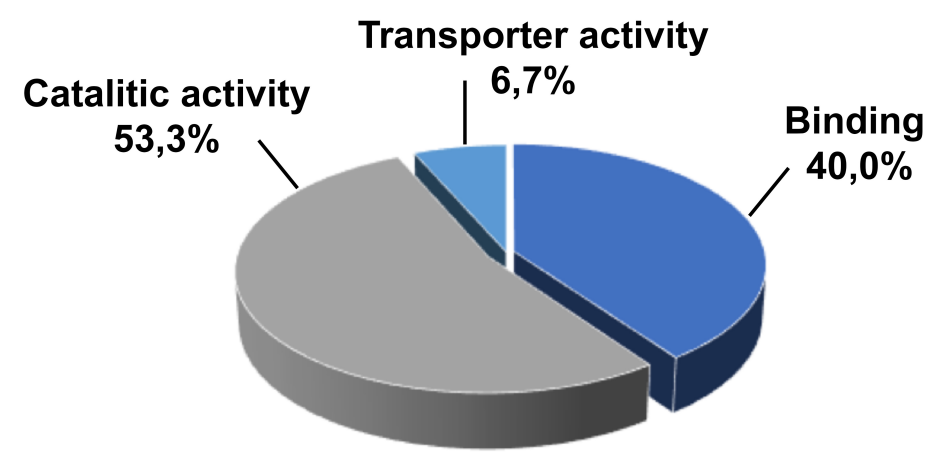

Terms INCREASED or ONLY expressed in ACID CONDITIONS

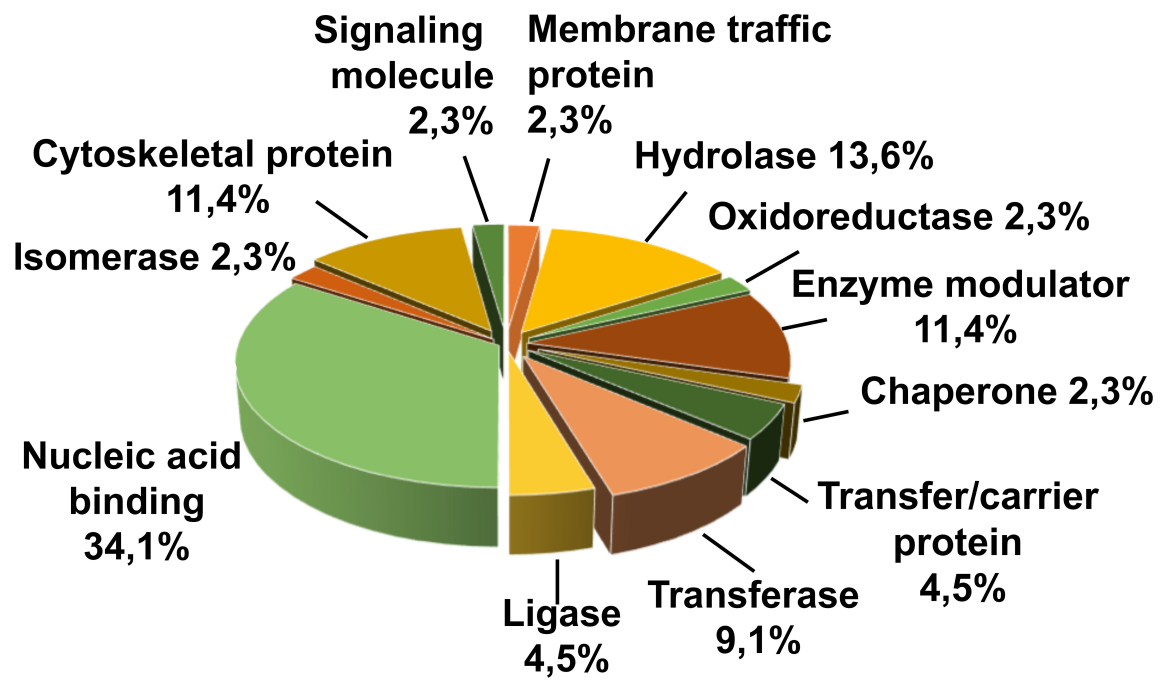

Terms DECREASED in ACID CONDITIONS or ONLY expressed in CONTROL
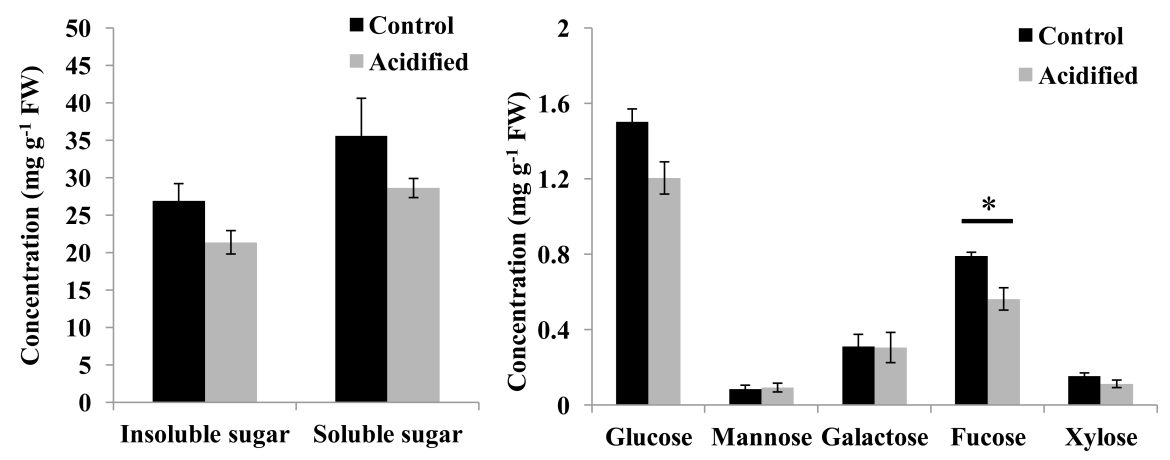

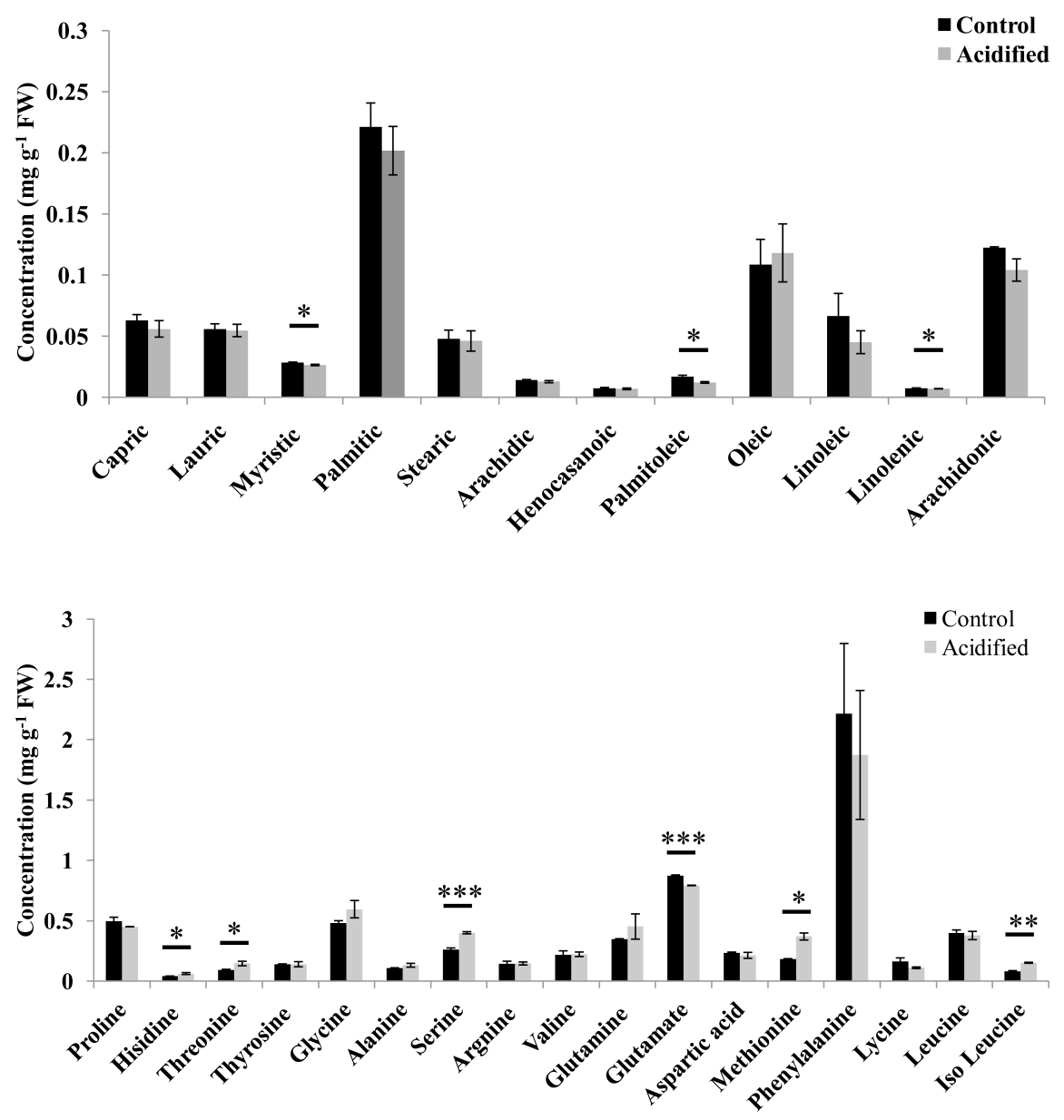